\title{
Petrol Fiyat Dalgalanmalarının Getiri Oynaklığı Üzerine Etkisi: Türkiye'de Alt Endeksler Üzerine Bir Uygulama
}

\author{
İsmail ÇELIK* \\ Arife ÖZDEMIR** \\ Nazlıgül GÜLCAN***
}

\section{ÖZET}

Çalışmada, 04.01.2000-18.03.2014 dönemi Kimya, Sinai, BIST 100 Endeksi ve Brent Petrol kapanış fiyat verileri ile petrol fiyatlarındaki değişimin hisse senedi piyasaları üzerindeki etkileri ortaya konulmaya çalışılmıştır. Brent Petrol fiyatlarındaki değişimin araştırma konusu yapılan endekslerdeki (BIST100, BISTSINAİ, BISTKIMYA) getiri oynakllğı üzerinde açıklayıcı bir değişken olup olmadiğının tespiti için kurulan ARMA-GARCH modellerinin varyans denklemine Brent Petrol fiyat değişimleri açıklayıcı değişken olarak ilave edilmiş, ARCH ve GARCH teriminin ciddi düzeyde bir değişme göstermediği ve Brent Petrol getirilerinin varyans denklemine ilave edilmesinden sonra katsayı negatif de olsa istatistiki olarak anlamlı olmadı̆̆ tespit edilmiştir. Bu sonuç, Brent Petrol fiyat değişimlerinin BIST100, BISTSINAİ ve BISTKIMYA getiri oynaklıklart üzerinde istatistiki olarak anlamlı bir etkisinin olmadığını kanitlamaktadır.

Anahtar Kelimeler: BIST-Kimya/Sınai/100 Endeksi, Brent Petrol \$/TL kapanıs fiyatı, ARCHGARCH, Volatilite.

JEL Sinıflandırması: C22, E44, Q43.

The Impact of Oil Price Fluctuations on Stock Return Volatility: An Application on Sub-Indices in Turkey

\section{ABSTRACT}

In this study, with data in the period of 04.01.2000-18.03.2014, which Chemical, Industrial, BIST 100 Index and closing price of Brent Oil changes in oil prices on the stock market has tried to expose the effects. Brent oil price changes in recent research conducted in these indices (BIST100, BISTSINAI, the BISTKIMYA) return volatility on the explanatory variable determining whether established for the ARMA-GARCH model, the variance equation Brent Oil price change as explanatory variables were added, ARCH and GARCH term did not show a significant change and Brent Oil is added to the variance equation after the coefficient of returns negative, although not statistically significant which have been identified. This result, on BIST100, BISTSINAI ve BISTKIMYA return volatility of Brent oil price changes prove not to be a statistically significant effect.

Keywords: BIST-Chemical, Industrial, BIST 100 Index, Brent Oil \$/TL closing price, ARCHGARCH, Volatility.

Jel Classification: C22, E44, Q43.

\footnotetext{
* Yrd. Doç. Dr. İsmail Çelik, Mehmet Akif Ersoy Üniversitesi, İktisadi ve İdari Bilimler Fakültesi, ismailcelik@mehmetakif.edu.tr

** Öğr. Gör. Arife Özdemir, Mehmet Akif Ersoy Üniversitesi, Bucak Hikmet Tolunay Meslek Yüksekokulu, aozdemir@mehmetakif.edu.tr

*** Öğr. Gör. Nazlıül Gülcan, Mehmet Akif Ersoy Üniversitesi, Tefenni Meslek Yüksekokulu, nazligulgulcan@mehmetakif.edu.tr
} 


\section{GíRIŞ}

Hisse senedi yatırımcıları açısından finansal piyasa oynaklığı, risk yönetimi, varlık tahsisi ve fiyatlandırma için teori ve uygulamanın merkezidir (Andersen vd., 2001: 44). Petrol fiyatlarında 1973 öncesinde çok fazla dalgalanma olmamasına ve büyük ABD petrol şirketlerinin bu tarihe kadar özellikle fiyat ve üretim kontrolleri vasıtasıyla petrol fiyatlarını 20. yüzyılın büyük bölümü boyunca aynı düzeyde tutulması ile ilgili çalışmalarına rağmen 6 Ekim 1973'de yaşanan Yom Kippur Savaşı'ndan sonra ham petrol üzerindeki kontrol ABD'den OPEC'e geçmiştir. Petrol fiyatlarındaki değişimin dünya ekonomisi üzerindeki etkisi oldukça büyüktür (Driesprong vd., 2008: 307). Petrol fiyatlarındaki değişim ve oynaklığın ekonomi ve finansal piyasalar üzerinde önemli etkileri olabilir. Petrol fiyatlarındaki herhangi bir artış petrolü ihraç eden ülke açısından, ihraç gelirlerinin artışından dolayı reel milli geliri arttırırken; petrolü ithal eden ülkeler açısından, daha fazla harcama yaratarak reel milli geliri azaltacaktır. Bu da petrol ithal eden ülkelerden petrol ihraç eden ülkelere gelir transferine sebep olacak ve ülkeler arasındaki gelir dengesizliğini artırıcı bir etki yapacaktır (Özkaya, 2001). Finansal piyasalar üzerinde; mal ve hizmet fiyatlarında da artışa neden olacak; talebin azalmasına bağlı bir üretim düşüşü ve bunun sonucunda da firma karlarının azalması ile hisse senedi fiyatlarını dalgalandıracaktır.

Finansal piyasa katılımcıları açısından volatilite ve şokların pazarlar arasında nasıl aktarıldığını bilmek önem arz etmektedir. Volatilite ve finansal zaman serileri arasında şokların iletimi bağlamında araştırmalar iki ana hat üzerinde yoğunlaşmıştır. Birinci hat, Eşbütünleşme analizi; farklı finansal piyasalar arasındaki uzun dönemli ortak hareketleri incelemek için benimsenmiştir. İkinci hat ise; hisse senedi fiyatları ve hisse senedi getirileri gibi finansal değişkenler açısından volatilitenin zamansal yolunu inceler. Araştırmacılar genellikle ARCH olarak bilinen otoregresif koşullu değişen varyans modellerinin sınıflandırılmış varyasyonlarını kullanarak zamanla değişen koşullu varyansı tahmin etmeye çalışmışlardır. Son yıllarda araştırmalar bir piyasadan diğerine hareket eden süreklilik ve volatilite üzerine yoğunlaşmıştır (Malik ve Ewing, 2009: 95). Türev fiyatlandırma, portföy optimizasyonu, risk yönetimi ve korunma için korelasyon ve volatilitenin iyi tahmin edilmesi gerekliliğinden dolayı modern finansın kalbinde volatilite tahminlemesi ve modellemesi yatmaktadir (Sadorsky, 2012: 248).

Bu çalışmada petrol fiyatlarında yaşanan değişimlerin Borsa İstanbul'da işlem gören hisse senedi getirileri üzerindeki etkisi temel ve alt endeksler bağlamında ARCH türevi modeller kullanılarak analiz edilmeye çalışılacaktır. Çalışmanın ilerleyen kısımlarında sırasıyla petrol fiyatları ile hisse senedi piyasaları arasındaki ilişkileri inceleyen literatüre değinilip daha sonra gerçekleştirilecek analizlere ilişkin metodoloji ve araştırma sonuçlarına yer verilecektir. 


\section{LITERATÜR ARAŞTIRMASI}

Petrol fiyatları ile hisse senedi getirileri arasındaki ilişkilere ilişkin literatür incelendiğinde konuya farklı metodolojilerle yaklaşan çalışmalara rastlanmaktadır. Araştırmaların bazılarında petrol ve hisse senedi getirileri arasındaki kısa ve uzun dönemli ilişkiler bir takım geleneksel yöntemler kullanılarak inceleme konusu yapılmışken, son dönemde ise söz konusu ilişkilerin volatilite ölçümleri veya volatilite yayılımları bağlamında incelendiği dikkat çekmektedir.

İşcan (2010), Kapusuzoğlu (2011), Adaramola (2012) ve Yıldırım vd. (2014) Johansen-Juselius eşbütünleşme ve Granger Nedensellik testlerini kullanarak petrol fiyatlarının hisse senedi getirileri üzerindeki etkisini incelemişler; İşcan (2010) hisse senedi fiyatları üzerinde petrol fiyatlarındaki değişmenin etkili olmadığı sonucunu bulurken diğerleri etkili olduğu sonucuna ulaşmışlardır.

Papapetrou (2001), Magyereh (2004), Cong vd. (2008), Park ve Ratti (2008), Le ve Chang (2011), Ono (2011), Dagher ve Hariri (2013)'de VAR Modelini kullanarak; Anorou ve Mustafa (2007), Miller ve Ratti (2009) 'da VECM Modelini kullanarak petrol fiyatlarının hisse senedi getirileri üzerindeki etkisini incelemişler ve petrol şoklarının hisse senedi fiyat hareketlerinin açıklanmasında önemli bir etkiye sahip olduğu sonucuna ulaşmışlardır. Berk ve Aydoğan (2012)'de VAR Modelini kullanarak; Apergis ve Miller (2009)'da VEC/VAR Modellerini kullanarak yaptıkları çalışmada petrol fiyatlarında meydana gelen bir değişmenin hisse senedi getirileri üzerinde herhangi bir etkiye sahip olmadığını ortaya koymuştur.

Volatilite modellerini kullanarak, Sadorsky (1999), Aloui ve Jammazi (2009), Malik ve Ewing (2009), Cifarelli ve Paladino (2010), Arouri vd. (2011), Filis vd. (2011), Arouri vd. (2012), Sadorsky (2012), Abdalla (2013) petrol fiyatları ve hisse senedi getirileri arasında anlamlı bir volatilite eğilimi olup olmadığını araştırmışlar ve petrol fiyatlarında değişikliğin hisse senedi fiyatlarını etkilediğini ortaya çıkarmışlardır.

Chittedi (2011) petrol fiyatları ve hisse senedi fiyatları arasındaki uzun dönemli ilişkiyi incelemek için ARDL modelini kullanmış ve petrol fiyatlarının hisse senedi fiyatları üzerinde herhangi bir etkiye sahip olmadığı sonucuna ulaşmıştır.

Arouri vd. (2010) doğrusal ve doğrusal olmayan modeller kullanarak petrol fiyatlarında meydana gelen şoklara karşı hisse senedi piyasalarının tepkilerini incelemeye çalışmışlardır. Arouri ve Fouquau (2009) doğrusal ve doğrusal olmayan ilişkiyi incelemişler bazı ülkelerde petrol fiyatlarındaki değişmenin hisse senedi piyasalarını etkilediği sonucunu bulurken bazı ülkelerde etkilemediğini kanıtlamıştır. 


\section{ARAŞTIRMANIN DIZZAYNI}

\subsection{Araştırmanın Amacı}

Araştırmada hedeflenen petrol fiyatlarındaki değişimin İstanbul Borsası'nda işlem gören Ulusal 100, Sınai ve Petro-Kimya endekslerindeki getiri oynaklığı üzerinde herhangi bir etkiye sahip olup olmadığının incelenmesidir.

\subsection{Araştırma Yöntemi}

Petrol fiyatları ile hisse senedi endeksleri arasındaki ilişkilerin EKK veya VAR, VEC ve Granger nedensellik testleri gibi eşanlı denklem sistemleriyle ortaya konulması analiz sonuçlarının güvenilirliğini zayıflatmaktadır. Zira elde edilen model sonuçlarında çoğu zaman değişen varyans sorunu yaşanabilmektedir. $\mathrm{Bu}$ sebeple son dönemde gerçekleştirilen çalışmalarda değişkenler arasındaki ilişkiler volatilite modelleri yardımıyla analize konu edilmektedir. Veri setinde varlığı tespit edilen ARCH etkisini dikkate alan modeller kullanılarak petrol fiyatlarındaki değişimin hisse senedi piyasaları üzerindeki etkileri ortaya konulmaya çalışılacaktır.

Analizlerin gerçekleştirilebilmesi, veri setlerinin durağan bir yapıya sahip olması ile doğrudan ilişkilidir zira durağan olmayan veri setleriyle çalışılması sahte regresyon sorununu ortaya çıkarabilir.

ARCH modeli tahmin edilirken karşılaşılan en büyük sorun koşullu varyans için çok sayıda hata terimi karesi gecikmesinin istatistiksel olarak anlamlı çıkması sonucu tahmin edilecek parametre sayısının artmasıdır ki bu da modelin kullanımını zorlaştırmaktadır (Akar 2007:206). ARCH modelinde karşılaşılan bu sorunu gidermek amacıyla Bollerslev (1986)'da GARCH modelini geliştirmiştir. GARCH(p,q) modeli; $\sigma_{t}^{2}=\alpha_{0}+\sum_{i=1}^{q} \alpha_{i} \varepsilon_{t-i}^{2}+\sum_{i=1}^{p} \beta_{i} \sigma_{t-i}^{2}$ şeklinde formüle edilir. $\operatorname{GARCH}(1,1)$ ise $\sigma_{t}^{2}=\alpha_{0}+\sum_{i=1}^{q} \alpha_{1} \varepsilon_{t-i}^{2}+\sum_{i=1}^{p} \beta_{1} \sigma_{t-i}^{2} \quad$ şeklinde kurulmaktadır. GARCH(p,q) modelinde, gecikmeli hata terimlerinin karelerine $\left(\varepsilon_{t-1}^{2}, \varepsilon_{t-2}^{2}, \ldots \ldots . \varepsilon_{t-q}^{2}\right)$ ilave olarak ARCH modelinden farklı olarak koşullu varyans terimlerinin gecikmeli değerleri $\left(\sigma_{t-1}^{2}, \sigma_{t-2}^{2}, \ldots . . . \sigma_{t-p}^{2}\right)$ de bulunmaktadır. Modelin anlamlılı̆g $, \mathrm{q}>0, \mathrm{p}>0 ; \alpha_{0}>0, \alpha_{i}>0$ ve $\beta_{i}>0$ şartının sağlanmasını ve $\alpha_{i}+\beta_{i}<0$ olmasını gerektirmektedir (Knight and Satchell, 2007: 47).

Modelde yer alan $\alpha_{i}$, bir önceki dönemde meydana gelen bilgi şoklarının t zamanda volatiliteye etkisini ifade etmekteyken, $\beta_{i}$ katsayısı ise söz konusu şok etkisinin kalıcılığını açıklamakta kullanılmaktadır. 


\subsection{Veri Seti}

Araştırmada kullanılan Brent Petrol Fiyat verileri investing.com adresinden, diğer endeks verileri ise Borsa İstanbul'un resmi internet sitesinden alınmış olup, 02.01.2003 ile 18.03.2014 tarihleri arasındaki Kimya Endeksi, BIST 100 Endeksi, Sinai Endeks ve Brent Petrol \$/TL kapanış fiyatlarından oluşmaktadır. Çalışmada toplam 2724 adet veri kullanılmıştır.

Veriler analiz edilmeden önce her birinin günlük logaritmik getirileri $\mathrm{LN}\left(\mathrm{P}_{\mathrm{t}} / \mathrm{P}_{\mathrm{t}-1}\right)$ formülü yardımıyla hesaplanmıştır.

\subsection{Araştırma Bulguları}

Veri setinin analizine geçmeden önce getiri serilerinin zamanyolu grafikleri şekil 1'de gösterilmektedir. Grafiklerden görüldüğü gibi getiri serileri sabit bir ortalama etrafında seyir takip etmektedir. Serilerin grafikleri incelendikten sonra Genişletilmiş Dickey-Fuller birim kök testi yardımıyla serilerin birim kök içerip içermedikleri incelenmiştir.

Şekil 1: GBISTKIMYA, GBIST100, GBISTSINAI ve GBRENT Verilerinin Zamanyolu Grafikleri
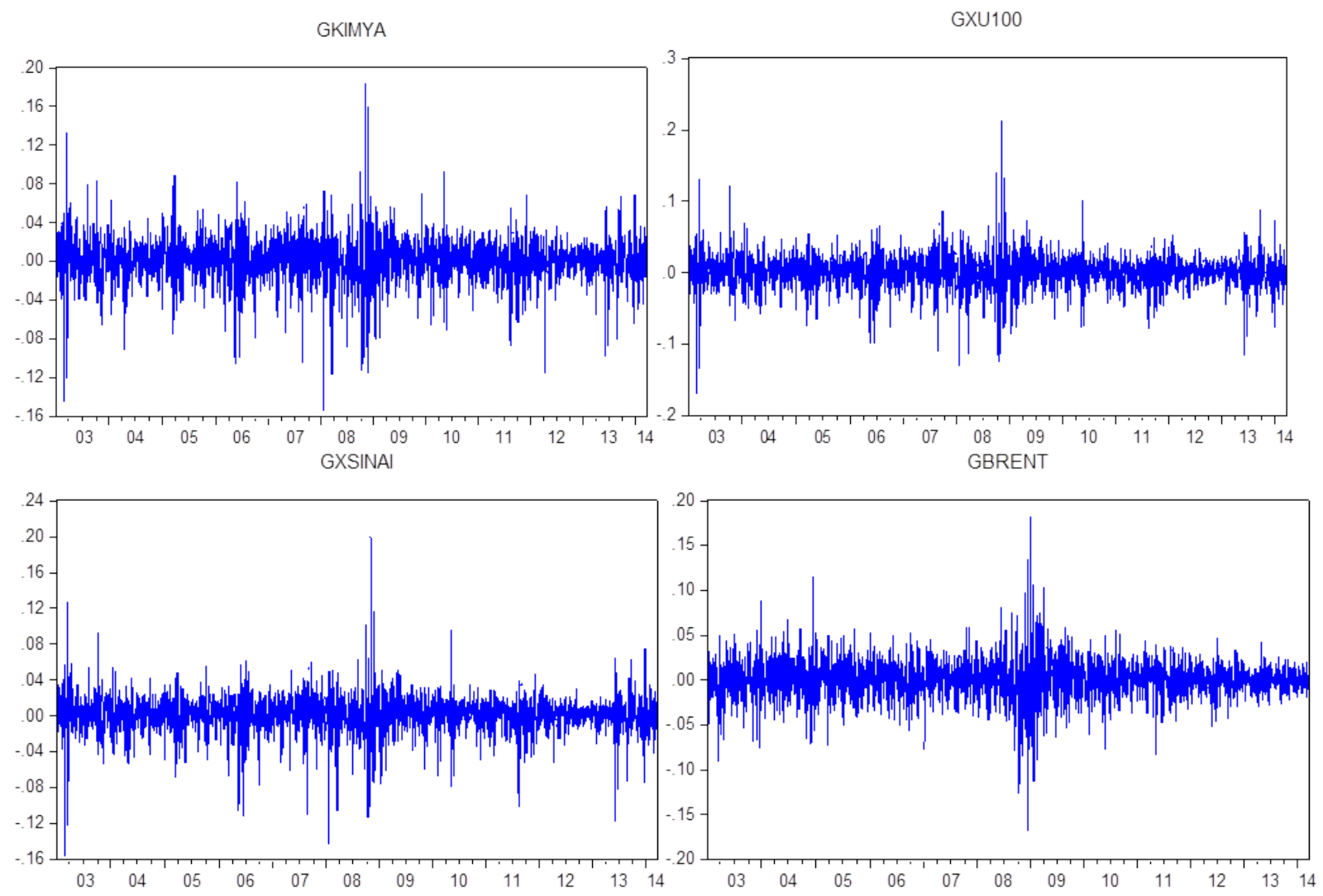
Tablo 1: Getiri Serilerinin Genişletilmiş Dickey Fuller (ADF) Birim Kök Test Sonuçları

\begin{tabular}{|c|c|c|c|c|c|}
\hline $\begin{array}{l}\text { Getiri } \\
\text { Serileri }\end{array}$ & t-istatistiği & Olasılık & $\begin{array}{l}\text { Getiri } \\
\text { Serileri }\end{array}$ & t-istatistiği & Olasillk \\
\hline BIST100 & $-49,076$ & $0,0001^{*}$ & BIST100 & $-49,117$ & $0,0000^{*}$ \\
\hline BISTSINAI & $-48,383$ & $0,0001^{*}$ & BISTSINAI & $-48,414$ & $0,0000^{*}$ \\
\hline BISTKIMYA & $-48,296$ & $0,0001^{*}$ & BISTKIMYA & $-48,312$ & $0,0000^{*}$ \\
\hline BRENT & $-51,838$ & $0,0001^{*}$ & BRENT & $-51,833$ & $0,0000^{*}$ \\
\hline 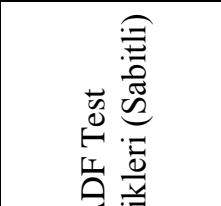 & \multicolumn{2}{|c|}{$-3,432(\% 1)$} & \multirow{3}{*}{ 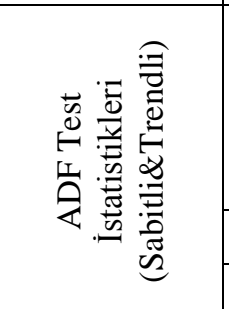 } & \multicolumn{2}{|c|}{$-3,961(\% 1)$} \\
\hline 《: & \multicolumn{2}{|c|}{$-2,862(\% 5)$} & & \multicolumn{2}{|c|}{$-3,411(\% 5)$} \\
\hline & \multicolumn{2}{|c|}{$-2,567$ (\%10) } & & \multicolumn{2}{|c|}{$-3,127(\% 10)$} \\
\hline
\end{tabular}

Tablo 1 incelendiği zaman tüm getiri serileri test istatistiğinin mutlak değer olarak tüm kritik değerlerden büyük olduğu görülmektedir. Kısaca söylemek gerekirse getiri serileri durağandır yani birim kök içermemektedir.

Serilerin durağanlıklarının testinden sonra volatilite modellerinin kullanılıp kullanılmayacağını tespit edebilmek için fiyat artışlarının/azalışlarının fiyat artışlarını/azalışlarını takip edip etmediği yani getiri serilerinde $\mathrm{ARCH}$ etkisinin var olup olmadığının tespiti gerekmektedir. Geleneksel zaman serisi modelleri sabit varyans temeline dayanmakteyken finansal zaman serilerinin varyansları zaman içerisinde değişkenlik gösterdiği için volatilite modelleri uygunluk arzetmektedir.

Getiri serileri için çeşitli ARMA modelleri kurulmuş ve modellerin anlamlılıkları dikkate alınarak getiri serileri için en uygun ARMA modelleri aşağıda sunulmuştur.

Tablo 2: Getiri Serilerinin ARMA Modelinin Tespitine İlişkin Regresyon Sonuçları

\begin{tabular}{|c|c|c|c|c|}
\hline $\begin{array}{c}\text { Bağımlı } \\
\text { Değişkenler }\end{array}$ & BIST100 & BISTSINAİ & BISTKİMYA & BRENT \\
\cline { 1 - 4 } Modeller & ARMA (0,1) & ARMA(0,1) & ARMA(0,1) & ARMA(2,2) \\
\cline { 1 - 4 } Parametreler & 0.000560 & 0,000549 & 0,000471 & 0,000445 \\
\cline { 1 - 4 } C & - & - & - & $0,272488^{*}$ \\
\hline$\emptyset_{1}$ & - & - & - & $-0,975355^{*}$ \\
\hline$\emptyset_{2}$ & $0.060740^{*}$ & $0,074458^{*}$ & $0,073128^{*}$ & $-0,268585^{*}$ \\
\hline$\theta_{1}$ & - & - & - & $0,965472^{*}$ \\
\hline$\theta_{2}$ & 0.003676 & 0,005566 & 0,005591 & 0,002929 \\
\hline$R^{2}$ & 0.003310 & 0,005200 & 0,005225 & 0,001460 \\
\hline Düzeltilmiş $R^{2}$ & -4.591058 & $-4,835814$ & $-4,616629$ & $-4,802179$ \\
\hline AIC & & &
\end{tabular}




\begin{tabular}{|c|c|c|c|c|}
\hline SIC & -4.586717 & $-4,831473$ & $-4,612289$ & $-4,791322$ \\
\hline Log Likelihood & 6252.725 & 6585,960 & 6287,540 & 6538,365 \\
\hline F Olasılığ & 0,001550 & 0,000098 & 0,000094 & 0,092729 \\
\hline ARCH-LM & 0,0000 & 0,0000 & 0,0000 & 0,0000 \\
\hline & $*=\% 1$ anlamlılık $* *=\% 5$ anlamlılık $* * *=\% 10$ anlamlılık \\
\hline
\end{tabular}

Getiri serilerinin her biri için en uygun koşullu ortalama denkleminin tahminin gerçekleştirilmesinde en küçük kareler (LS) yöntemi kullanılarak en uygun AIC ve SIC değerine sahip modeller tablo 2'de sunulmuştur. Buna göre her bir getiri serisi için tahmini yapılan koşullu denklem eşitlikleri aşağıdaki gibidir.

$$
\begin{gathered}
\text { Getiri BIST100 }=0,000560+0,060740 * \text { MA }(1) \\
\text { Getiri BISTSINAİ }=0,000549+0,074458 * \text { MA }(1) \\
\text { Getiri BISTKİMYA }=0,000471+0,073128 * \text { MA }(1)
\end{gathered}
$$

Getiri BRENT $=0,000445+0,272488 * A R(1)-0,975355 * A R(2)-0,268585 * \mathrm{MA}(1)$

$$
+0,965472 * \mathrm{MA}(2)
$$

Yukarıdaki tabloda sunulan koşullu denklem parametrelerinde yer alan AR ve MA terimleri $\% \quad 1$ anlamlılık düzeyinde anlamlı olduğu ve $\operatorname{AR}(1)+\operatorname{AR}(2)+\ldots<1$ ve $\mathrm{MA}(1)+\mathrm{MA}(2)+\ldots<1$ koşulunun tüm denklemler için sağlandığı kanıtlanmıştır. Tüm koşullu denklem sonuçlarının akabinde değişen varyansın olup olmadığının tespiti için ARCH-LM testleri uygulanmış ve tablonun en altında sunulmuştur. ARCH-LM testi sonuçları tüm getiri serilerinden değişen varyans sorununun olduğunu göstermektedir. Değișen varyans sorununun varlığı altında volatilite modellerinin (ARCH-GARCH) çalıştırılması gerekmektedir.

BIST100, BISTSINAİ, BISTKİMYA ve BRENT getiri serilerinin tamamında değișen varyans probleminin ortaya çıkması sonucunda volatilite modellemesine gidilmiştir. Getiri serileri normal dağılıma sahip olmadığı için student $t$ dağılımına göre gerçekleştirilen modellemelerde tüm getiri serileri için en uygun modelin GARCH $(1,1)$ olduğu tespit edilmiştir. Her bir getiri serisi için kurulan ARMA GARCH modelleri ve tanısal test sonuçları tablo 3'de sunulmuştur.

Tablo 3: Getiri Serilerine İlişkin ARMA GARCH(1,1) Tahmin Sonuçları

\begin{tabular}{|c|c|c|c|c|}
\hline $\begin{array}{c}\text { Bağımlı } \\
\text { Değişkenler }\end{array}$ & BIST100 & BISTSINAİ & BISTKIMYA & BRENT \\
\hline $\begin{array}{c}\text { Modeller } \\
\text { Parametreler }\end{array}$ & $\begin{array}{c}\text { ARMA(0,1) } \\
\text { GARCH(1,1) }\end{array}$ & $\begin{array}{c}\text { ARMA(0,1) } \\
\text { GARCH(1,1) }\end{array}$ & $\begin{array}{c}\text { ARMA(0,1) } \\
\text { GARCH(1,1) }\end{array}$ & $\begin{array}{c}\text { ARMA(2,2) } \\
\text { GARCH(1,1) }\end{array}$ \\
\hline $\begin{array}{c}\text { Ortalama } \\
\text { Denklemi }\end{array}$ & \multicolumn{5}{|l}{} \\
\hline $\mathrm{C}$ & $0,001820^{*}$ & $0,002229^{*}$ & $0,001965^{*}$ & $0,000813^{* *}$ \\
\hline$\emptyset_{1}$ & - & - & - & $0,278001^{*}$ \\
\hline
\end{tabular}




\begin{tabular}{|c|c|c|c|c|}
\hline$\emptyset_{2}$ & - & - & - & $-0,997400 *$ \\
\hline$\theta_{1}$ & $0,065275^{*}$ & $0,078035^{*}$ & $0,067632 *$ & $-0,277478^{*}$ \\
\hline$\theta_{2}$ & - & - & - & 0,998138* \\
\hline \multicolumn{5}{|l|}{$\begin{array}{l}\text { Varyans } \\
\text { Denklemi }\end{array}$} \\
\hline$\alpha_{0}$ & 0,0000176* & 0,0000162* & 0,0000213* & 0,00000143* \\
\hline$\alpha_{1}$ & $0,104041^{*}$ & $0,134522^{*}$ & $0,110564 *$ & $0,037972^{*}$ \\
\hline$\beta_{1}$ & 0,865806* & 0,834189* & 0,855375* & 0,959157* \\
\hline$R^{2}$ & 0.001305 & 0,000352 & 0,002192 & 0,003394 \\
\hline Düzeltilmiş $R^{2}$ & 0.000938 & 0,000015 & 0,001826 & 0,001926 \\
\hline AIC & -4.868717 & $-5,204056$ & $-4,892503$ & $-5,060160$ \\
\hline SIC & -4.855696 & $-5,191035$ & $-4,879482$ & $-5,040617$ \\
\hline Log Likelihood & 6634,758 & 7091,322 & 6667,143 & 6893,348 \\
\hline $\mathrm{Q}(12)$ & 0,315 & 0,246 & 0,388 & 0,869 \\
\hline ARCH-LM & 0,5484 & 0,2355 & 0,2057 & 0,8200 \\
\hline
\end{tabular}

Tablo 3 incelendiğinde piyasaya giren iyi ya da kötü yeni bir bilginin BIST100 getiri endeksi üzerindeki etkisinin \%10,40, söz konusu şokun kalıcılığının \%86,58 olduğu, ayrıca BISTSINAI getiri endeksi üzerindeki şok etkisinin \%13,45, söz konusu şokun kalıcılığının ise $\% 83,42$ olduğu, BISTKIMYA getiri endeksi serisi üzerindeki etkisinin ise \%11,06, söz konusu şokun kalıcılığının ise \%85,54 olduğu, BRENT petrol getiri endeksi üzerindeki etkisinin ise \%3,79 ve söz konusu şokun kalıcılığının da \%95,92 olduğu kanıtlanmıştır. Kurulan modellerin bir bütün olarak herhangi bir spesifikasyon hatası içerip içermediği tanısal testler yardımıyla araştırılmış ve tablo 3'ün alt kısmında sunulmuştur her bir model için 12 gecikmeli Q test sonuçları modelden elde edilen artıkların otokorelasyon içermediğini göstermektedir. Gerçekleştirilen ARCH-LM test sonuçlarına göre ise model artıklarında herhangi bir değişen varyans sorunu yoktur.

BRENT petrol fiyatlarındaki değişimin araştırma konusu yapılan endekslerdeki getiri oynaklığı üzerinde açıklayıcı bir değişken olup olmadığının tespiti için kurulan ARMAGARCH modellerinin varyans denklemine BRENT petrol getiri serisi açıklayıcı değişken olarak ilave edilmiş ve analiz sonuçları tablo 4'de ayrıntısıyla sunulmuştur. Veri setleri normal dağılıma uymadığı için model tahminlemesi student-t dağılımına göre gerçekleştirilmiştir. 
Tablo 4: BRENT Serisinin Varyans Denklemine İlave Edildiği ARMA GARCH(1,1) Model Sonuçları

\begin{tabular}{|c|c|c|c|}
\hline $\begin{array}{c}\text { Bağımlı } \\
\text { Değişkenler }\end{array}$ & BIST100 & BISTSINAİ & BISTKİMYA \\
\hline $\begin{array}{c}\text { Modeller } \\
\text { Parametreler }\end{array}$ & $\begin{array}{c}\text { ARMA(0,1) } \\
\text { GARCH(1,1) }\end{array}$ & $\begin{array}{c}\text { ARMA(0,1) } \\
\text { GARCH(1,1) }\end{array}$ & $\begin{array}{c}\text { ARMA(0,1) } \\
\operatorname{GARCH}(1,1)\end{array}$ \\
\hline \multicolumn{4}{|l|}{$\begin{array}{l}\text { Ortalama } \\
\text { Denklemi }\end{array}$} \\
\hline $\mathrm{C}$ & 0,001824* & $0,002263 *$ & $0,002003^{*}$ \\
\hline$\emptyset_{1}$ & - & - & - \\
\hline$\emptyset_{2}$ & - & - & - \\
\hline$\theta_{1}$ & $0,065192 *$ & 0,077803* & $0,067175^{*}$ \\
\hline$\theta_{2}$ & - & - & - \\
\hline \multicolumn{4}{|l|}{$\begin{array}{l}\text { Varyans } \\
\text { Denklemi }\end{array}$} \\
\hline$\alpha_{0}$ & 0,0000177* & 0,0000166* & $0,0000226^{*}$ \\
\hline$\alpha_{1}$ & 0,103909* & $0,134789 *$ & 0,111853* \\
\hline$\beta$ & 0,865956* & 0,833416* & 0,852083* \\
\hline BRENT & $-0,000133$ & $-0,000324$ & 0,000417 \\
\hline$R^{2}$ & 0.001291 & 0,000139 & 0,002009 \\
\hline Düzeltilmiş $R^{2}$ & 0.000924 & 0,000229 & 0,001642 \\
\hline AIC & -4.868058 & $-5,203999$ & $-4,892376$ \\
\hline SIC & -4.852867 & $-5,188808$ & $-4,877185$ \\
\hline Log Likelihood & 6634,861 & 7092,245 & 6667,971 \\
\hline $\mathrm{Q}(12)$ & 0,329 & 0,286 & 0,410 \\
\hline ARCH-LM & 0,5762 & 0,2649 & 0,2459 \\
\hline
\end{tabular}

Tablo 4'de Brent petrol getiri endeksi açıklayıcı değişken olarak modele ilave edildiği zaman $\mathrm{ARCH}$ teriminin ve GARCH teriminin ciddi düzeyde bir değişme göstermediği görülmektedir. Ayrıca BRENT petrol getirilerinin varyans denklemine ilave edilmesinde sonra katsayı her ne kadar negatif de olsa istatistiki olarak anlamlı olmadığı tespit edilmiştir. $\mathrm{Bu}$ sonuç Brent Petrol fiyat değişimlerinin BIST100, BISTSINAİ ve BISTKİMYA getiri oynaklıkları üzerinde istatistiki olarak anlamlı bir etkisinin olmadığını kanıtlamaktadır. Kurulan modellere ilişkin tanısal test sonuçlarına göre model artıklarının otokorelasyon sorununa sahip olmadığı ve değişen varyans problemi içermediği ayrıca görülmektedir.

\section{SONUÇ}

Yatırımcılar açısından volatilitenin tahmin edilmesi riskten korunma açısından oldukça önemli bir yer tutmaktadır. Finans yazınında volatilitenin tahminine yönelik çok 
sayıda çalı̧̧ma yapılmaktadır. Bu çalışmada da petrol fiyatlarında yaşanan iyi/kötü yönlü herhangi bir değişmenin hisse senedi getiri endeksleri üzerinde harhangi bir etkisi olup olmadığı analiz edilmiştir. Öncelikle getiri serilerinin zamanyolu grafikleri incelenerek serilerin ortalama etrafinda bir seyir izlediği tespit edilmiş daha sonra serilerin durağan olup olmadıkları Genişletilmiş Dickey-Fuller birim kök testleri ile test edilmiş ve serilerin birim kök içermedikleri bulunmuştur. Serilerin durağanlıklarının testinden sonra volatilite modellerinin kullanılıp kullanılamayacağını tespit edebilmek yani ARCH etkisinin var olup olmadığını test etmek için ARMA modelleri kurulmuştur. Getiri serilerinin her biri için en uygun koşullu ortalama denkleminin tahminin gerçekleştirilmesinde en küçük kareler (LS) yöntemi kullanılarak en uygun AIC ve SIC değerine sahip modeller belirlenmiştir. Tüm getiri serilerinde değişen varyans sorunu olduğu yapılan ARCH-LM testi ile ortaya çıkmış ve volatilite modellemesine gidilmiştir. Getiri serileri normal dă̆ılıma sahip olmadığı için student $t$ dağılımına göre gerçekleştirilen modellemelerde tüm getiri serileri için en uygun modelin GARCH $(1,1)$ olduğu tespit edilmiştir. piyasaya giren iyi yada kötü yeni bir bilginin BIST100 getiri endeksi üzerindeki etkisinin $\% 10,40$, söz konusu şokun kalıcılığının $\% 86,58$ olduğu, ayrıca BISTSINAI getiri endeksi üzerindeki şok etkisinin \%13,45, söz konusu şokun kalıc1lı̆ının ise $\% 83,42$ olduğu, BISTKIMYA getiri endeksi serisi üzerindeki etkisinin ise $\% 11,06$, söz konusu şokun kalıc1lığının ise \%85,54 olduğu, BRENT petrol getiri endeksi üzerindeki etkisinin ise $\% 3,79$ ve söz konusu şokun kalıcıllğının da \%95,92 olduğu kanıtlanmıştır.

BRENT petrol fiyatlarındaki değişimin araştırma konusu yapılan endekslerdeki getiri oynaklı̆̆ı üzerinde açıklayıcı bir değişken olup olmadığının tespiti için kurulan ARMAGARCH modellerinin varyans denklemine BRENT petrol getiri serisi açıklayıcı değişken olarak ilave edilmiş ARCH ve GARCH terimlerinde ciddi düzeyde bir değişme gözlenmediği sonucuna ulaşılmıştır. Ayrıca BRENT petrol getirilerinin varyans denklemine ilave edilmesinden sonra katsayı her ne kadar negatif de olsa istatistiki olarak anlamlı olmadığı tespit edilmiştir. Bu sonuç Brent Petrol fiyat değişimlerinin BIST100, BISTSINAİ ve BISTKIMYA getiri oynaklıkları üzerinde istatistiki olarak anlamlı bir etkisinin olmadığını göstermektedir.

Analiz sonuçları doğrultusunda petrol fiyatlarındaki değişikliklerin hisse senedi getirileri üzerinde bir etkisinin bulunmadığı kanıtlanmışıır. Bu sonuçlar literatürdeki Apergis ve Miller (2009), İşcan (2010), Chittedi (2011), Aydoğan (2012)'ın çalışmalarıyla aynı sonucu verse de Sadorsky (1999), Papapetrou (2001), Magyereh (2004), Anorou ve Mustafa (2007), Cong vd. (2008), Park ve Ratti (2008), Aloui ve Jammazi (2009), Malik ve Ewing (2009), Miller ve Ratti (2009), Cifarelli ve Paladino (2010), Arouri vd. (2011), Filis vd. (2011), Kapusuzoğlu (2011), Le ve Chang (2011), Ono (2011), Arouri vd. (2012), Adaramola (2012), Sadorsky (2012), Abdalla (2013), Dagher ve Hariri (2013), Yıldırım vd. (2014)'nin yaptıkları çalışmalardan farklı sonuçlar vermektedir. Yapılan analizlerde farklı sonuçlar ortaya çıkmasında analizlerin yapıldığı ülkelerin ekonomik durumlarının farklı olması etkili 
olduğu kadar kullanılan analiz yöntemlerinin farklılıklar göstermesi, analizlerin yapıldığı dönemlerin farklı olması da etkili olmuştur.

\section{KAYNAKLAR}

Abdalla, Suliman Zakaria Suliman (2013), "Modelling the Impact of Oil Price Fluctuations on the Stock Returns in an Emerging Market: The Case of Saudi Arabia', Interdisciplinary Journal of Research in Business, No. 10, pp. 10- 20.

Adaramola, Anthony, Olugbenga (2012), “Oil Price Shocks and Stock Market Behaviour: The Nigerian Experience”, J Economics, No. 3(1), pp. 19-24.

Akar, Cüneyt (2007), "Volatilite Modellerinin Öngörü Performansları: Arch, Garch ve Swarch Karşılaştırması”, Bandırma Üniversitesi Bandırma İşletme Fakültesi Dergisi, Cilt 8 Say1 2, s. 201-217.

Aloui, Chaker - Jammazi, Rania (2009), "The Effects of Crude Oil Shocks on Stock Market Shifts Behaviour: A Regime Switching Approach”, Energy Economics, Vol. 31, No. 5, pp. 789-799.

Andersen, Torben G.- Bollerslev, Tim - Diebold, Francis X. - Ebens, Heiko (2001), "The Distribution of Realized Stock Return Volatility’, Journal of Financial Economics, No. 61, February, pp. 44.

Anoruo, Emmanuel - Mustafa, Muhammad (2007), “An Empirical Investigation Into The Relation of Oil to Stock Market Prices”, North American Journal of Finance and Banking Research, No. 1, pp. 22-36.

Apergis, Nicholas - Miller, Stephen M. (2009), "Do Structural Oil-Market Shocks Affect Stock Prices?’, Energy Economics, Vol. 31, No. 4, March, pp. 569-575.

Arouri, Mohamed El Hédi - Julien, Fouquau (2009), “On the Short-Term İnfluence of Oil Price Changes on Stock Markets in GCC Countries: Linear and Nonlinear Analyses', Economics Bulletin, Vol. 29, No. 2, May, pp. 795-804.

Arouri, Mohamed El Hédi - Lahiani, Amine - Bellalah, Makram (2010), “Oil Price Shocks and Stock Market Returns in Oil-Exporting Countries: The Case of GCC Countries", International Journal of Economics and Finance, Vol. 2, No. 5, November, pp. 132139.

Arouri, Mohamed El Hedi - Jouini, Jamel - Nguyen, Duc Khuong (2011), "Volatility Spillovers between Oil Prices and Stock Sector Returns: Implications for Portfolio Management”, Journal of International Money and Finance, Vol. 30, No. 7, pp. 13871405.

Arouri, Mohamed El Hedi.- Jouini, Jamel .- Nguyen , Duc Khuong (2012),” On the impacts of oil price fluctuations on European equity markets: Volatility spillover and hedging effectiveness”, Energy Economics, Vol. 34, No. 2, pp. 611-617. 
Bollerslev, Tim (1986), “Generalized Autoregressive Conditional Heteroskedasticity”, Journal of Econometrics, No. 31, North-Holland, pp. 307-327

Berk, İstemi - Aydoğan, Berna (2012), “Crude Oil Price Shocks and Stock Returns: Evidence from Turkish Stock Market under Global Liquidity Conditions”, Institute of Energy Economics at the University of Cologne (EWI), Sayı 12/15, Eylül, http://www.ewi.unikoeln.de/fileadmin/user_upload/Publikationen/Working_Paper/EW I_WP_12/15_Crude_Oil_price_shocks_01.pdf ,( 21.04.2014).

Chittedi, Krishnareddy (2011), “Does Oil Price Matter for Indian Stock Markets?”, Munich MPRA Personal Repec Archive, No. 35334, November, pp. 1-13.

Cifarelli, Giulio - Paladino, Giovanna (2010), “Oil Price Dynamics and Speculation A Multivariate Financial Approach’’, Energy Economics, Vol. 32, No. 2, pp. 363-372.

Cong, Rong-Gang - Wei, Yi-Ming - Jiao, Jian-Lin - Fan Ying (2008), "Relationships Between Oil Price Shocks and Stock Market: An Empirical Analysis from China', Energy Policy, Vol. 36, No.9, July, pp. 3544-3553.

Dagher, Leila - Hariri, Sadika El (2013), “The İmpact of Global Oil Price Shocks on the Lebanese Stock Market’, Energy, Vol. 63, November, pp. 366-374.

Driesprong, Gerben - Jacobsen, Ben - Maat, Benjamin (2008), "Striking Oil: Another Puzzle?’, Journal of Financial Economics, Vol. 89, No. 2, August, pp. 307-327.

Filis, George - Degiannakis, Stavros - Floros, Degiannakis (2011), “Dynamic Correlation Between Stock Market and Oil Prices: The Case of Oil-İmporting and Oil-Exporting Countries”, International Review of Financial Analysis, Vol. 20, No. 3, June, pp. 152164.

İşcan, Erhan (2010), “Petrol Fiyatının Hisse Senedi Piyasası Üzerindeki Etkisi”, Maliye Dergisi, Say1. 158, Ocak-Haziran 2010, s. 607-617.

Kapusuzoğlu, Ayhan (2011), "Relationships between Oil Price and Stock Market: An Empirical Analysis from Istanbul Stock Exchange (ISE)', International Journal of Economics and Finance, Vol. 3, No. 6, November, pp. 99-106.

Knight, John - Satchell, Stephen (2007), Forecasting Volatility in the Financial Markets, Elsevier Ltd., USA.

Le, Thai-Ha - Chang, Youngho (2011), “The İmpact of Oil Price Fuctuations on Stock Markets in Developed and Emerging Economies', Munich Personal RePEc Archive, No. 31753, June,http://mpra.ub.uni-muenchen.de/31753/1/MPRA_paper_31753.pdf (18.04.2014).

Maghyereh, Aktham (2004), “Oil Price Shocks and Emeging Stock Markets: A generalized VAR Approach”, International Journal of Applied Econometrics and Quantitative Studies, Vol. 1, No. 2, pp. 27-40. 
Malik, Farooq - Ewing, Bradley T. (2009), "Volatility Transmission Between Oil Prices and Equity Sector Returns”, International Review of Financial Analysis, Vol. 18, No. 3, March, pp. 95-100.

Miller, J. Isaac - Ratti, Ronald A. (2009), “Crude Oil and Stock Markets: Stability, İnstability, and Bubbles”, Energy Economics, Vol. 31, No. 4, January, pp. 559-568.

Ono, Shigeki (2011), “Oil Price Shocks and Stock Markets in BRICs, The European Journal of Comparative Economics"', The European Journal of Comparative Economics, Vol. 8, No. 1, pp. 29-45.

Özkaya, Şule (2001), “Petrol Fiyatlarının Ekonomilere Etkisi”, Uluslararası Ekonomik Sorunlar Dergisi, Sayı. 1.

http://www.mfa.gov.tr/petrol-fiyatlarinin-ekonomilere-etkisi.tr.mfa (11.02.2015).

Papapetrou, Evangelia (2001), “Oil Price Shocks, Stock Market, Economic Activity and Employment in Greece’, Energy Economics, Vol. 23, No. 5, September, pp. 511-532.

Park, Jungwook - Ratti, Ronald, A. (2008), “Oil Price Shocks and Stock Markets in the U.S. and 13 European Countries”, Energy Economics, Vol. 30, No. 5, September, pp. 2587-2608.

Sadorsky, Perry (1999), “Oil Price Shocks and Stock Market Activity”, Energy Economics, Vol. 21, No. 5, pp. 449-469.

Sadorsky, Perry (2012), “Correlations and Volatility Spillovers Between Oil Prices and The Stock Prices of Clean Energy and Technology Companies”, Energy Economics, Vol. 34, No. 1, January, pp. 248-255.

Yıldırım, Murat - Bayar, Yılmaz - Kaya, Abdülkadir (2014), “Enerji Fiyatlarının Sanayi Sektörü Hisse Senedi Fiyatları Üzerindeki Etkisi: Borsa İstanbul Sanayi Sektörü Şirketleri’’, Muhasebe ve Finansman Dergisi, Sayı 62, Nisan, s. 93-108. 
